\title{
YUCCA MOUNTAIN PROJECT - SCIENCE \& TECHNOLOGY RADIONUCLIDE ABSORBERS DEVELOPMENT PROGRAM OVERVIEW
}

Hong-Nian Jow ${ }^{1}$, Robert C. Moore ${ }^{1}$, Katheryn B. Helean ${ }^{1}$, Shas Mattigod ${ }^{2}$, Michael Hochella, Jr. ${ }^{3}$, Andrew R. Felmy ${ }^{2}$, Jun Liu', Kevin Rosso ${ }^{2}$, Glen Fryxell ${ }^{2}$, James Krumhansl ${ }^{1}$, and Yifeng Wang ${ }^{1}$

${ }^{1}$ Sandia National Laboratory

${ }^{2}$ Pacific Northwest National Laboratory

${ }^{3}$ Virginia Polytechnic Institute and State University

\section{ABSTRACT}

The proposed Yucca Mountain repository is anticipated to be the first facility for long-term disposal of commercial spent nuclear fuel and high-level radioactive waste in the United States. The facility, located in the southern Nevada desert, is currently in the planning stages with initial exploratory excavations completed. It is an underground facility mined into the tuffaceous volcanic rocks that sit above the local water table. The focus of the work described in this paper is the development of radionuclide absorbers or "getter" materials for neptunium (Np), iodine (I), and technetium (Tc) for potential deployment in the repository. "Getter" materials retard the migration of radionuclides through sorption, reduction, or other chemical and physical processes, thereby slowing or preventing the release and transport of radionuclides. An overview of the objectives and approaches utilized in this work with respect to materials selection and modeling of ion "getters" is presented. The benefits of the "getter" development program to the United States Department of Energy (US DOE) are outlined.

\section{INTRODUCTION}

The proposed Yucca Mountain repository (YMR), located in southern Nevada, is to be the first facility for permanent disposal of spent reactor fuel and high-level radioactive waste in the United States. U.S. Environmental Protection Agency (EPA) regulations (40 CFR Part 197-64, 64 FR 46976) require the U.S. Department of Energy (DOE) to evaluate peak doses resulting from the potential release of radionuclides from the repository for 10,000 years [1]. Over this time period, Total Systems Performance Assessment (TSPA) analysis has indicated that among the major radionuclides contributing to dose are technetium, iodine, and neptunium, all of which may be highly mobile in the environment. Containment of these radionuclides within the repository is a priority for the Yucca Mountain Project (YMP). Toward this end, the Office of Science and Technology International (OSTI) at DOE's Office of Civilian Radioactive Waste Management (OCRWM) has initiated a program to develop "getters" (radionuclide sorbents), to be placed in the invert beneath the waste canisters with the intention of enhancing sequestration of these mobile radionuclides within the repository.

The overall objectives of the proposed research are to: (1) select potential "getter" materials based on likely efficacy, cost, and stability in projected repository 
environments (with respect to both physical and chemical characteristics); (2) use nanoengineering approaches to enhance sorption capabilities of the selected materials; (3) rigorously test the performance of the engineered materials in repository-relevant environments; (4) develop mechanistic model(s) to provide insight into the long-term viability and robustness of performance with regard to changing environmental conditions; and (5) engineer the ion "getter" materials into an appropriate form for potential site deployment. The product of this research will be a recipe and placement guide for a radionuclide sorbent application that will provide defense in depth in the improbable, but possible, event of a breached waste container.

The proposed research is a joint, multidisciplinary effort with Sandia National Laboratory (SNL), as lead laboratory in collaboration with Pacific Northwest National Laboratory (PNNL), and Virginia Polytechnic Institute and State University (additional collaborators are to be added as the program matures). Sandia will focus on developing, and then testing, the "getter" potential of novel mesoporous (typically $>200 \mathrm{~nm}$ ) silicatebased phases, layered double metal hydroxides (hydrotalcite derivatives), and multi-metal hydroxides and oxides. Pacific Northwest National Laboratory will develop and test nanoporous (typically $<200 \mathrm{~nm}$ ) "getter" materials, focusing mainly on titanium, zirconium, and lanthanum phosphates. Virginia Polytechnic Institute and State University will investigate layered and tunneled manganese oxides as potential "getter" materials. Laboratory studies will be supplemented by thermodynamic modeling, surface complexation modeling, atomic scale ( $a b$ initio) modeling and molecular modeling of "getter" material surface interactions with solids, dissolved species, and solution chemistry.

The program is currently envisioned as a five-year effort that will, ultimately, encompass not only materials development but also testing and qualifying of selected "getter" materials under repository-relevant conditions. However, in the program's first year (Fiscal Year, FY-04), the emphasis has been on defining research directions, synthesis of potentially promising "getter" materials, and screening of their performance. Successes in these areas will be reviewed along with a general overview of the program's five-year research strategy.

\section{RESEARCH OBJECTIVES AND APPROACH}

\section{"GETTER" MATERIALS SELECTION}

The primary objective of this work is to develop and/or identify materials that can effectively sequester Np, I and Tc under Yucca Mountain repository (YMR) conditions. Among the materials to be evaluated are apatites, layered double hydroxides (LDH), copper, iron, magnesium and manganese oxides as well as nanoporous and mesoporous synthetic materials. A multidisciplinary approach will be utilized drawing from materials science, geochemistry and nanoscience. The initial efforts (FY04/05) will focus on the synthesis, characterization, and screening of potential "getters". 


\section{Hydroxyapatite "Getters"}

SNL has been investigating the sorption properties of hydroxyapatite, $\mathrm{Ca}_{5}\left(\mathrm{PO}_{4}\right)_{3} \mathrm{OH}, P 2_{1} / \mathrm{b}, \mathrm{Z}=2$, for the last five years. Hydroxyapatite has the ability to sequester $\mathrm{Np}, \mathrm{Pu}$, and $\mathrm{U}$ at ambient conditions with reported $\mathrm{K}_{\mathrm{d}}$ values up to $10^{6} \mathrm{l} / \mathrm{mole}$ [2]. Significant Tc sorption was also observed for bone-derived apatite when $\mathrm{SnCl}_{2}$ was used as a reducing agent. It is, however, unclear whether these sorption properties will persist for long times under the relatively harsh YMR invert conditions. Of primary concern is whether or not hydroxyapatite can sequester $\mathrm{Tc}$ in an oxidizing environment.

Synthesis, characterization, and testing of the radionuclide sequestration properties of a suite of hydroxyapatite is underway, including $\mathrm{Fe}(\mathrm{II})$ and $\mathrm{Sn}$ (II) treated materials. Tc sequestration from YMR relevant fluids at invert relevant temperatures is being measured. Ultimately, the mechanism of Tc sorption will be examined and the long-term performance of hydroxyapatite as a function of elevated temperatures, radiation damage, and variable fluid compositions will be determined.

During the remainder of FY04 and continuing into FY05 the emphasis will be on assessing the relative ability of Fe-doped apatite materials to scavenge radionuclides, including $\mathrm{Np}(\mathrm{V})$ and $\mathrm{Pu}(\mathrm{VI})$. Sorption experiments will be performed as a function of hydroxyapatite crystallinity, surface area, and aliovalent metal dopant concentrations. For materials with promising sequestration properties at ambient temperatures, additional tests will be conducted over a range of temperatures $\left(22^{\circ} \mathrm{C}\right.$ to $\left.95^{\circ} \mathrm{C}\right)$. In addition to powder X-ray diffraction (XRD) and transmission electron microscopy (TEM), hydroxyapatite will be characterized by Brunauer, Emmett, and Teller analysis (BET) to determine surface areas, Fourier-transformed infrared spectroscopy (FT-IR) and Mossbauer spectroscopy to verify the valence state of the iron. Solubility of the hydroxyapatite as a function of $\mathrm{pH}$ and temperature will be determined by inductively coupled plasma mass spectrometry (ICP-MS), and ion chromatography (IC), when other anions $\left(\mathrm{F}^{-}, \mathrm{Cl}^{-}\right)$are suspected of having substituted on the hydroxide site. FY06 studies will be more directed to developing an in-depth understanding of the retention mechanisms of the best candidate materials and toward quantifying the extent (or lack thereof) of desorption expected in different environments. Efforts for FY07 and FY08 include refining the "getter" for YMR conditions, and performing long-term sorption studies in hostile conditions. Ultimately, the mechanism of Tc sequestration will be examined and the long-term performance of hydroxyapatite as a function of elevated temperatures, radiation damage, and variable fluid compositions will be determined.

\section{Iodine "Getters"}

Although not as abundant as Tc-99, the proposed YMR will also contain a substantial inventory of I-129 that, ideally, should be contained within the repository workings. Developing iodine scavengers for placement in the invert beneath the waste canisters will follow several approaches. Past studies on this topic have shown that certain copper-containing materials do, in fact, scavenge iodide from solution, but performance envelopes are unknown at present. Essentially the same status can be 
accorded to the scavenging ability of conventional hydrotalcite minerals (mixed metal hydroxides that act as anion exchangers), as well as the performance of hydrotalcites where non-traditional metals have been substituted into the normal hydrotalcite formulation. Optimizing the performance of materials developed along the lines established by previous studies will provide the basis for the proposed research.

Past SNL studies have identified several materials as sorbents for iodine that are based on 1) layered double hydroxides (LDH) with rather exotic chemistries (incorporating $\mathrm{Bi}$ and $\mathrm{Zr}$ in addition to the traditional $\mathrm{Mg}$ - $\mathrm{Al}$ normally used in hydrotalcite formulations) and 2) the ability of copper oxides (and possibly hydroxides) to retain iodine. In this task, these leads will be followed and the scope of the investigation broadened by synthesizing and evaluating other materials with related chemistries and structures. Various candidate materials will be tested as iodine sorbents through kinetic (flow-through) and batch (static) equilibrium experiments.

Structures of these materials will be determined by scanning electron microscopy (SEM) and TEM (particle morphology), BET (surface area), XRD (crystal structure) and Zeta potential (polarity of particle surface charges in different fluids). ICP-MS will be used to determine the solubility of substrate materials and their sorption capacity for iodine. For layered materials, the impact of altering interlayer environments through the use of polyoxometalate ions will also be explored. Iodine uptake rates and longer-term equilibration experiments will be carried out as a function of temperature, iodine concentration, iodine to sorbent ratio, and in the presence of potentially competing ions that may exist in YMR relevant fluids. Iodine speciation (e.g., $\mathrm{I}^{-}$vs. $\mathrm{IO}_{3}{ }^{-}$) will be assessed by comparing total dissolved iodine (from ICP-MS) with iodide ( $\mathrm{I}^{-}$) analyses obtained using an iodide specific ion electrode. As with the preceding task, this work will continue into FY05/06. FY07/08 studies will be more directed to developing an indepth understanding of the retention mechanisms of the best candidate materials and toward quantifying the extent (or lack thereof) of desorption expected in different environments. Throughout the study, a limited number of $\mathrm{ReO}_{4}{ }^{-}$batch sorption tests will also be carried out to screen for materials that could possibly contribute to other tasks directed at immobilizing pertechnetate, $\mathrm{TcO}_{4}^{-}$.

\section{Layered Double Hydroxides}

LDH materials show significant promise for the uptake of anions such as pertechnetate, $\mathrm{TcO}_{4}^{-}$and iodate, $\mathrm{IO}_{3}^{-}$, from water. Their sequestration potential is attributed, in part, to their high point of zero charge (PZC), the $\mathrm{pH}$ at which the particles exhibit no net surface charge. The PZC for many LDH materials is greater than $\mathrm{pH} 12$. LDH materials also exhibit high interlayer anion exchange capability. In addition, past studies have amply demonstrated that a wide variety of responses to radionuclide uptake may be obtained depending on the synthesis process and the bulk chemistry of the materials. At present, however, no systematic approach is available that allows a researcher to determine, in advance, optimal compositions and formulation strategies. 
The primary objective of this task is to synthesize a diverse range of LDH materials by varying synthesis conditions and chemistry (e.g. chemical composition of layer-forming metals and anions introduced during synthesis, preparation methods, surfactant templating, and post-synthesis treatment) in order to optimize material compositions and structures for the sorption of $\mathrm{TcO}_{4}^{-}$and $\mathrm{IO}_{3}^{-}$anions. The capacity and rate of anion sorption/desorption on the $\mathrm{LDH}$ materials as a function of material composition, structure and solution chemistry will be measured (FY 05/06). The focus will be to understand the mechanisms of anion interactions with $\mathrm{LDH}$ surfaces and interlayers and to determine the stability of LDH materials under the chemical conditions expected in the YMR invert (the primary objective) and possibly in other relevant environments. This will be the focus of this study in FY 07/08.

Materials synthesis will focus on $\mathrm{Mg}: \mathrm{Al}$ or $\mathrm{Zn:Al} \mathrm{LDH}$, and the green rusts (hydrotalcites based on $\mathrm{Fe}$ (II) and $\mathrm{Fe}$ (III)). In addition to these, an evaluation of the potential for using the following combinations: $\mathrm{Mg}: \mathrm{Fe}(\mathrm{III}), \mathrm{Zn}: \mathrm{Fe}(\mathrm{III}),(\mathrm{Zn}, \mathrm{Mg}): \mathrm{Al}$, $\mathrm{Mg}:(\mathrm{Al}, \mathrm{Fe}(\mathrm{III}))$, and $\mathrm{Fe}(\mathrm{II}): \mathrm{Al}$ will be evaluated. Mixed formulations of $(\mathrm{Zn}, \mathrm{Mg}): \mathrm{Al}$ and $\mathrm{Mg}:(\mathrm{Al}, \mathrm{Fe}(\mathrm{III}))$ may offer useful combinations of properties.

With the formulation of $\mathrm{Fe}(\mathrm{II}): \mathrm{Al}$, both anion sorption and anion reduction can be integrated into a single $\mathrm{LDH}$ material. $\mathrm{Fe}(\mathrm{II})$-containing materials are able to reduce $\mathrm{Tc}(\mathrm{VII})$ to $\mathrm{Tc}(\mathrm{IV})$ and $\mathrm{Se}(\mathrm{VI})$ to $\mathrm{Se}(\mathrm{IV}), \mathrm{Se}(\mathrm{II})$, or even $\mathrm{Se}(0)$. Anion sorption should further enhance these reductions by increasing the probability of the interactions of $\mathrm{Tc}(\mathrm{VII})$ and Se(VI) species with Fe(II) in the material. Therefore, it is expected Fe(II):Al LDH will have much higher sorption capacity for Tc(VII) than other materials.

Within the general formula $\mathrm{M}(\mathrm{II})_{1-\mathrm{x}} \mathrm{M}(\mathrm{III})_{\mathrm{x}}(\mathrm{OH})_{2} \mathrm{Y}_{\mathrm{x} / \mathrm{n}}$, where $\mathrm{M}$ is a di- or trivalent cation and $\mathrm{Y}$ is an anion, the ratio $(1-\mathrm{x})$ : $\mathrm{x}$ for any given $\mathrm{LDH}$ will vary over the range between $2: 1$ and 3:1. This variation will affect anion uptake in several different ways. As a simple exercise, we might compare the effect of high charge density (small $\mathrm{M}(\mathrm{II}): \mathrm{M}(\mathrm{III})$ ratio) to the reduction of inter-ionic spacing in an ionic crystal, stabilizing the system. However, high charge density will not alter the nearest anion-M(III) distance, but will reduce the anion-anion distance, increasing repulsion. In addition, high charge density may have the effect of squeezing out interlayer water, which may be important in stabilizing retention of the anion. Finally, an observation has been made that anions on occasion exhibit more steric hindrance than would have been expected. In these circumstances, the $\mathrm{M}(\mathrm{II}): \mathrm{M}(\mathrm{III})$ ratio must be optimized by experiment. There is every reason to expect that the optimum ratio will vary with the choice of target anion, and it will be interesting to find out whether, for a given anion, the ratio varies with choice of metals. Thus, a second experimental variable to be investigated is whether it is possible to enhance the selectivity of a $\mathrm{LDH}$ "getter" for $\mathrm{ReO}_{4}{ }^{-}$(a surrogate for $\mathrm{TcO}_{4}{ }^{-}$), $\mathrm{I}^{-}$ or $\mathrm{IO}_{3}^{-}$by altering the residual positive charges on the hydrotalcite layers through chemical substitutions.

An effective LDH "getter" will only result if the anion(s) initially resident in the interlayer positions are more loosely bound than the target anion(s). Thus, an LDH with interlayer chloride will be acceptable for the removal of anions such as $\mathrm{SeO}_{4}{ }^{2-}$, but 
relatively ineffectual for the removal of most monovalent anions. Further, the initial presence of interlayer carbonate will inhibit the uptake of all of the target anions, except to the extent that these are adsorbed or exchanged onto external surfaces. Calcining removes all the indigenous interlayer anions including carbonate. On rehydration, they are replaced with hydroxide, or whatever other anions may also be present in the solution used to rehydrate the hydrotalcite. The nature of the substituting anions has been shown to impact the ability of the newly hydrated material to selectively scavenge pertechnetate.

The proposed work will require intensive characterization of material compositions and structures. In addition to routinely-used XRD, and SEM analyses, high resolution transmission electron microscopy (HRTEM) can provide information about compositional and structural changes on a molecular (meso) to nanometer scale, which will be particularly valuable for the correlation of material reactivity to material structure.

\section{Manganese Oxide "Getters"}

In nature it has been observed that various manganese oxide minerals are highly effective scavengers for a host of different trace constituents likely to be found in moderately "fresh" ground waters, as well as in seawater. The NanoGeoscience and Technology Lab in the Department of Geosciences at Virginia Tech, will be employed to explore whether the ability to scavenge trace constituents exhibited by various layer and tunnel structure manganese (III, IV) oxides can be adapted to the removal of the anionic aqueous species of ${ }^{129} \mathrm{I},{ }^{99} \mathrm{Tc}$ and ${ }^{237} \mathrm{~Np}$ from the relevant fluids under the expected conditions of the YMR invert.

Extensive sorption experiments using synthetic vernadite, (Mn(IV), $\mathrm{Fe}(\mathrm{III}), \mathrm{Ca}$, $\mathrm{Na})(\mathrm{O}, \mathrm{OH})_{2} \bullet \mathrm{n}\left(\mathrm{H}_{2} \mathrm{O}\right)$, and birnessite, $(\mathrm{Na}, \mathrm{Ca}, \mathrm{K})_{\mathrm{x}}[\mathrm{Mn}(\mathrm{IV}), \mathrm{Mn}(\mathrm{III})]_{2} \mathrm{O}_{4} \cdot 1.5\left(\mathrm{H}_{2} \mathrm{O}\right)$, on $\mathrm{ReO}_{4}^{-}$(as a surrogate for $\mathrm{TcO}_{4}{ }^{-}$) and non-radioactive I aqueous species will be conducted (FY 05/06). These experiments will also be performed with synthetic cryptomelane, $\mathrm{K}(\mathrm{Mn}(\mathrm{IV}), \mathrm{Mn}(\mathrm{II}))_{8} \mathrm{O}_{16}$, a $\mathrm{Mn}$-oxide with a tunnel structure, that also shows promise as a "getter". The sorption experiments will be run in flow-through reactors, where solutions at various temperatures, $\mathrm{pH}$, and ionic strength bearing the aqueous complex of interest will pass through a bed of the sorbent mineral. The effluent solution will be analyzed using aqueous spectroscopic methods. The reacted solids will be analyzed using microscopy (field emission scanning electron microscopy (FE-SEM); and TEM), structure analysis (XRD), bulk chemical spectroscopy (energy dispersive spectroscopy (EDS)), and surface sensitive spectroscopy (X-ray photoelectron spectroscopy (XPS)). The sorption efficiency for each material will be measured, and the reactivity of each phase as a function of external BET surface area will be calculated. The sorption efficiency of anionic species in these phases will be compared with respect to one another, and also as a function of crystallinity and crystal size of the same phase (FY 07/08). 


\section{Nanoporous Phosphate "Getters" for Tc, Np, and I}

This task will be performed by PNNL and represents a continuation and expansion of activities already in progress. Developing "getters" based on the concept of nanoporous titanium or zirconium phosphate phases is the primary objective of this work. The PNNL team has extensive experience with the design, synthesis and performance evaluation of nanoporous heavy metal and radionuclide sorbent materials. The mesoporous $\mathrm{Ti}$ and $\mathrm{Zr}$ phosphate materials are known to be anion exchange materials, and they have been targeted for this application since they are inherently bifunctional materials.

Although a few templated nanoporous (i.e. high surface area) phosphate phases are already under investigation, there are many more possibilities. Examples of nanostructured phosphate phases made to date include titanium, zirconium, iron, aluminum, vanadium and gallium phosphates. At present, the full capability of these materials to scavenge and retain radionuclides is not known. Previous work by PNNL staff has shown that certain mesoporous phosphates have superior sorbent properties for sequestering actinides. Of particular interest are the nanoporous $\mathrm{V}, \mathrm{La}$ and $\mathrm{Bi}$ phosphates.

Modifications of these materials can be obtained by introducing defects into the crystal lattices of the nanoporous substrate. Defects can play a critical role in the surface chemistry of reactive sites (e.g., catalyst reactivity). These defects can be installed by varying the stoichiometry of the phosphate phase, by redox processes, by radiation damage, or by adding dopants (either cationic or anionic). The chemical affinity and physical stability of a nanoporous metal phosphate phase will be dependent on the surface charge (which, in turn, is related to stoichiometry and/or oxidation state). Stoichiometry will be systematically varied to evaluate its impact on the sorption behavior, capacity and overall stability of the "getter" candidate. In addition, defects will be introduced by doping the material. Defects that distort the lattice may be introduced by substituting $\mathrm{Bi}(\mathrm{III})$, or other lanthanides, for lanthanum. Positively charged defects (with an affinity for anions) may be introduced by substituting $\mathrm{Ce}(\mathrm{IV})$ into (La, Bi) $\mathrm{PO}_{4}$ or $\mathrm{Nb}(\mathrm{V})$ into $\mathrm{Ti}(\mathrm{IV})$ and $\mathrm{Zr}(\mathrm{IV})$ containing materials. These substitutions allow for a combination of "hard" and "soft" Lewis acid sites to be incorporated into the mesoporous phosphate lattice

The "hard" Lewis acids ( $\mathrm{Ti}$ and $\mathrm{Zr}$ ) provide phosphate materials with the ability to bind "hard" anions (e.g. pertechnetate and periodate), while the phosphate backbone provides a receptive interface for binding cationic actinide species. In contrast to previous work at PNNL, these materials require no functionalization with organic ligands for their binding affinity; the mesoporous backbone is inherently functional for the radionuclides of interest. The small pore size of the templated nanoporous structure will prevent bacterial or enzymatic access to the bound radionuclide.

Modification of these nanoporous "getter" materials to create a hierarchical pore structure (large pores leading to small pores) will be carried out by using superposition of 
templating strategies. For example, the use of cellulosic derivatives or the vascular structure of wood in combination with the surfactant templating strategy outlined previously could be used. This task will explore these hierarchical templating methods to synthesize the nanoporous structured metal phosphates. This approach is complimentary to the strategy taken by our SNL collaborators for making hierarchical pore structures using the self-assembly of nanocrystals. By exploring these parallel pathways, we believe that we can develop optimized "getter" structure more efficiently.

In FY05/06 we propose to synthesize and evaluate various templated nanoporous and doped lanthanide phosphates as candidate "getter" materials. In FY07-08 the study will be expanded to examine the viability of nanoporous iron, vanadium and bismuth phosphates as "getter" materials.

\section{Mesoporous Tc and I "Getters"}

The SNL team has extensive experience with the design, synthesis and performance evaluation of nanoporous and mesoporous heavy metal sorbent materials. Many of these materials are known to be anion exchange materials, and have been targeted for this application because they can be functionalized with inorganic ligands for $\mathrm{TcO}_{4}{ }^{-}$selectivity. The development of nanoporous and mesoporous materials with inorganic functional groups for selective Tc sorption is the primary objective of this work.

In FY05 work will involve: 1) Synthesis of nanoporous silicotitanate and silicozirconate materials, 2) Inorganic functionalization of nanoporous materials, 3) Characterization of the material's pore structure by TEM, surface area by BET, structure by small angle XRD, and 4) Thermal, hydrolytic and acid and base stability. In FY06 and FY07, materials that appear to be candidate sorbents for technetium will be refined and optimized. Finally, these materials will be tested with multiple radionuclides under simulated repository chemical conditions (FY08). This work will be performed in the SNL Nanotechnology Laboratory.

\section{MODELING ACTIVITIES FOR ION-"GETTER" DEVELOPMENT}

\section{Modeling LDH Long-term Performance}

Because of the long YMR performance period, it is impossible to experimentally address many questions that may be raised regarding the future history of the repository and the long-term performance of "getter" materials. Thus, it is of vital importance to develop a suite of computational models that will give insights into these various processes that are not limited by the fact that very long-term predictions are required. The proposed modeling activities have in common that they will all be focused on developing appropriate tools to support experimental data integration and long-term performance assessments of LDH and other "getter" materials. 
Five specific modeling activities are planned: (1) Quantum mechanical modeling: $a b$ initio calculations will be performed to obtain a better understanding of the interactions of $\mathrm{TcO}_{4}{ }^{-}$with internal surfaces of $\mathrm{LDH}$ materials. (2) Classical fluid molecular dynamics: Simulations based on the density functional theory will be performed to investigate the behaviors of both solvent and ions within confined environments internal to LDH with various interlayer spacing. (3) Surface complexation model: Based on sorption data and molecular modeling results, we will extend the existing surface complexation models to a nano-confinement environment in $\mathrm{LDH}$, using parameters determined from the molecular modeling calculations above and from sorption experiments. (4)Thermodynamic modeling: This activity focuses on developing a thermodynamic model for layered double hydroxides (LDH). This model will predict the Gibbs free energy of formation of LDHs and phase stability as a function of compositions of both (layer-forming) cations and interlayer anions. (5) Adaptation of the EQ3/6 database to model the aqueous speciation of Tc, I, and $\mathrm{Np}$ in the unique range of solutions likely to occur in the invert. This will include development and incorporation of Pitzer activity coefficients specific to these fluid chemistries, assembly of association constants for various complexes of Tc and $\mathrm{Np}$ with ligands likely to occur in abundance in invert fluids (it is unlikely that iodine will form complexes), and accounting for the redox behavior of the various constituents (radionuclides and major components) in such fluids.

\section{Ab initio Modeling of Tc Interactions with Ti/Zr Phosphate Surfaces}

The $a b$ initio modeling of chemical interactions at the solid-liquid interface is a rapidly expanding field which has already shown substantial progress in developing mechanistic understandings of chemical processes that, previously, were known only from empirical observations. Modeling of Tc binding on nanoporous Ti/Zr phosphate "getters" will be conducted at PNNL to provide molecular-scale quantities as input parameters for thermodynamic modeling studies. Collectively, these modeling studies will be used to formulate mechanistic interpretations of experimental $\mathrm{TcO}_{4}{ }^{-}$uptake data collected previously at PNNL. The feedback of modeling into experiments will form a basis for generating improved design considerations. Insights into the basic mechanisms of radonuclide scavenging will also provide a basis for judging performance that is independent of the time constraints (and reaction kinetics) that are inherent in any laboratory study. The overall objectives and approaches of the $a b$ initio modeling studies are to provide realistic surface structures for the pore walls of the $\mathrm{Ti} / \mathrm{Zr}$ phosphate materials and to determine likely binding conformations of $\mathrm{TcO}_{4}{ }^{-}$on these surfaces.

Model input structures will be generated using a combination of the available crystallographic data for $\mathrm{Ti} / \mathrm{Zr}$ phosphates or close analogues and crystal chemical principles. Candidate surface structures will be refined exactly and the energetics computed by periodic structure optimization at the density functional level of ab initio theory, including an explicit treatment of an overlying bulk water phase and surface protonation/hydroxylation. In these calculations, the effects of metal cation substitutions ( $\mathrm{La}, \mathrm{V}, \mathrm{B}, \mathrm{Fe}$ ) on the surface structure, protonation, and energetics will be examined. In parallel, calculations on relevant solution monomers and attempts to establish linear free energy relationships between calculated protonation energies and experimental acidity 
constants will be performed. This information will serve to feed parameters into thermodynamic modeling of the surface functional groups and charging properties.

$A b$ initio molecular dynamics simulations on periodic slabs will be used to determine approach trajectories and to follow the integrity of the water solvation shell surrounding $\mathrm{TcO}_{4}{ }^{-}$in the vicinity of the $\mathrm{Ti} / \mathrm{Zr}$ surface. These calculations will yield information of the specific binding groups and binding energies for input into the thermodynamic models.

\section{Speciation and Bonding of Tc in Nanoporous "Getter" Materials}

Identifying the compositions, stoichiometries, and charges of aqueous sorbate species is critical for a comprehensive understanding of sorption phenomena. An improved understanding of the chemistry of speciation of ${ }^{99} \mathrm{Tc}$, in waste package leachates and the sorbed form will provide crucial data for designing better "getter" interface with enhanced Tc sorption performance and long-term stability. The types of Tc aqueous species that are known to exist in bulk electrolyte solutions and their thermochemical properties have been critically reviewed and compiled by Rard et al. (1991) [3]. However, a recent study of nanoporous alumina has indicated that the electrolyte properties in nanopores may differ significantly from bulk electrolyte properties due to overlapping double layers that exist in nanopores [4]. At present, the effect of nanopore confinement on sorbed speciation of Tc is not known. Therefore, to understand the interfacial chemistry of the nanoporous sorbents (potential "getter" materials), it is necessary to know the types of complex forms and the nature of binding of Tc and other risk driver species sorbed onto the nanoporous surface sites. Such speciation data will provide valuable input for improved development of "getter" materials and more accurate adsorption modeling being proposed by SNL (chemical modeling) and PNNL (molecular modeling). The primary objective of this study is to determine the nature of Tc species in electrolyte within the nanopores, and to examine mechanisms of Tc bonding to the nanoporous surface structure. Changes in nanoporous dimensions in response to $\mathrm{Tc}$ adsorption, and the effect of variations in $\mathrm{pH}$ and ionic strength on nanoporous structure and surface charge development will also be measured.

To address these questions, a detailed study of the local atomic environment both before and after the Tc species are bound to the nanoporous materials will be performed. Selected nanoporous phosphate materials of different pore size will be used in experimental studies to determine the variations of surface charge development and Tc binding with nanoporous dimensions. The studies on surface charge development will be conducted as a function of $\mathrm{pH}$ and ionic strength ( $\mathrm{NaCl}$ concentration). The nanoporous materials before and after study will be examined by XRD and extended X-ray absorption fine-structure (EXAFS) and X-ray absorption near edge structure (XANES) spectroscopy to determine changes in surface and bulk structure resulting from exposure to solutions of different $\mathrm{pH}$ and ionic strength. These studies will thus allow us to correlate changes in nanoporous structure (either induced by changes in solution composition or synthesis techniques) with changes in Tc uptake and surface charge development. The information on surface charge development is necessary to develop 
surface complexation models of the nanoporous "getters". In this regard, molecular simulations of the nanoporous phosphates will also be performed to both identify possible sites for Tc binding as well as proton binding energies to different sites on the surface. The proton binding energies and Tc binding positions can then be used as guides to the parameterization of the surface complexation models. This combined experimental, molecular modeling, and surface complexation modeling approach will allow unique molecular level insight to be obtained into the mechanisms of Tc uptake by the "getter" materials.

\section{KINETIC AND EQUILIBRIUM SORPTION EXPERIMENTS FOR I AND TC}

Past studies into the performance of various "getter" materials have shown repeatedly that the uptake of radionuclides is seldom either instantaneous or readily reversible. Yet, it is the end-state of such systems that will determine whether "getters" will be effective over the geologic time spans relevant to repository performance. Developing a standardized testing protocol for measuring the performance of Tc and I sorbents under YMR relevant conditions is the primary focus of this task. These protocols will be used to provide kinetic and equilibrium sorption experiments on materials developed at SNL with the ultimate intent of answering the question of whether the materials will remain functional for thousands of years.

This task entails measuring sorption kinetics and equilibrium loading (Tc, I) for materials provided by the SNL Nanotechnology Laboratory and development of iodine sorbents. Experiments will include batch sorption measurement as a function of technetium and iodine concentrations, solid to solution ratios, and temperature. For successful candidates, work will involve quantification of radionuclide releases into solutions that are initially unspiked. This includes development of standardized testing protocols for use by all groups designed to provide consistent data to the modeling effort.

\section{“GETTER" PROGRAM SUMMARY}

A summary of the primary research objectives and approaches utilized in the YMP "getters" program is reported in Table 1. This multidisciplinary, collaborative research project has, as its main objective, the identification, development and eventual deployment of "getters" designed to sequester Tc, I, and Np for up to 10,000 years, the regulatory timeframe defined by US EPA and US DOE [1]. Toward that end, several promising candidate materials are the focus of intense research in synthesis, characterization and evaluation as radionuclide sorbents. Research continues to evaluate the efficacy of hydroxyapatite, layered double hydroxides, $\mathrm{Mn}$ and other metal oxides/hydroxides, $\mathrm{Ti}$ and $\mathrm{Zr}$-phosphates, silicotitanate and silicozirconate materials as radionuclide sorbents. In addition to bulk materials, meso- and nanoporous materials are being engineered to optimize their selectivity and sequestration capabilities for the target radionuclides. Recent efforts focus on incorporating sorption and structural data into empirical models in order to better understand the mechanisms of radionuclide sorption onto the candidate "getters". These models will, eventually, allow long-term assessments of "getters" stability under YMR relevant conditions. 
Table 1. Summary of research objectives for each fiscal year for the YMP "getters" project.

\begin{tabular}{|c|c|c|c|c|}
\hline FY 04 & FY 05 & FY 06 & FY 07 & FY 08 \\
\hline \multicolumn{5}{|l|}{ Hydroxyapatite } \\
\hline $\begin{array}{l}\text { Evaluate sorption of } \\
\text { actinides in natural } \\
\text { systems. Begin } \\
\text { synthesis of modified } \\
\text { apatites. Initiate } \\
\text { screening studies to } \\
\text { determine sorption of } \\
\text { Tc. }\end{array}$ & $\begin{array}{l}\text { Continue screening } \\
\text { studies adding Np. } \\
\text { Begin performing } \\
\text { kinetics, sorption and } \\
\text { desorption } \\
\text { experiments on } \\
\text { modified apatites. }\end{array}$ & $\begin{array}{l}\text { Perform extensive } \\
\text { testing of the } \\
\text { sorption behavior of } \\
\text { modified apatites. } \\
\text { Begin tests under } \\
\text { YMR conditions. } \\
\text { Begin investigating } \\
\text { sorption } \\
\text { mechanisms. } \\
\end{array}$ & $\begin{array}{l}\text { Evaluate interactions } \\
\text { with waste package } \\
\text { corrosion products. } \\
\text { Continue sorption } \\
\text { desorption in } \\
\text { relevant fluids. } \\
\text { Evaluate processes } \\
\text { for large-scale } \\
\text { fabrication. }\end{array}$ & $\begin{array}{l}\text { Evaluate effects of } \\
\text { elevated radiation, } \\
\text { temperature, etc. } \\
\text { Perform long-term } \\
\text { sorption studies. } \\
\text { Perform long-term } \\
\text { leaching studies } \\
\text { under hostile } \\
\text { conditions. }\end{array}$ \\
\hline \multicolumn{5}{|l|}{ Iodine "getters" } \\
\hline $\begin{array}{l}\text { Develop screening } \\
\text { protocol for } \\
\text { identifying } \\
\text { promising iodine } \\
\text { getters. Develop } \\
\text { analytical techniques } \\
\text { for distinguishing } \\
\text { between iodide }\left(\mathrm{I}^{-}\right) \\
\text {and iodate }\left(\mathrm{IO}_{3}^{-}\right) \text {. } \\
\text { Begin synthesis of } \\
\text { novel LDH. }\end{array}$ & $\begin{array}{l}\text { Initiate synthesis and } \\
\text { screening of iodine } \\
\text { getters based on } \mathrm{Cu} \\
\text { and } \mathrm{Bi} \text {. Initiate } \\
\text { studies to identify } \\
\text { scavenging } \\
\text { mechanisms and } \\
\text { address reaction } \\
\text { kinetics for the most } \\
\text { promising materials. }\end{array}$ & $\begin{array}{l}\text { Continue studies to } \\
\text { identify iodine } \\
\text { scavenging } \\
\text { mechanisms for the } \\
\text { most promising } \\
\text { materials. Define } \\
\text { protocols that will be } \\
\text { used to certify iodine } \\
\text { getters for inclusion } \\
\text { in the YMR invert. }\end{array}$ & $\begin{array}{l}\text { Complete studies to } \\
\text { identify iodine } \\
\text { scavenging } \\
\text { mechanisms and } \\
\text { address reaction } \\
\text { kinetics. Initiate } \\
\text { testing to address } \\
\text { fabrication issues for } \\
\text { large-scale } \\
\text { deployment. }\end{array}$ & $\begin{array}{l}\text { Complete } \\
\text { certification } \\
\text { experiments on all } \\
\text { promising materials. } \\
\text { Resolve fabrication } \\
\text { issues and associated } \\
\text { economic } \\
\text { implications. }\end{array}$ \\
\hline \multicolumn{5}{|c|}{ Layered double hydroxides (LDH) } \\
\hline $\begin{array}{l}\text { Begin synthesis and } \\
\text { testing of LDH } \\
\text { materials for sorption } \\
\text { of actinides and Tc. }\end{array}$ & $\begin{array}{l}\text { Conduct adsorption } \\
\text { tests including } \\
\text { kinetics and isotherm } \\
\text { studies. Evaluate } \\
\text { sorption capacities of } \\
\text { promising LDH } \\
\text { materials. }\end{array}$ & $\begin{array}{l}\text { Study } \\
\text { sorption/desorption } \\
\text { behavior under YMR } \\
\text { relevnet conditions. } \\
\text { Begin physical and } \\
\text { chemical stability } \\
\text { tests. }\end{array}$ & $\begin{array}{l}\text { Optimize LDH based } \\
\text { on results of previous } \\
\text { studies. Conduct } \\
\text { adsorption tests } \\
\text { using corrosion } \\
\text { products. }\end{array}$ & $\begin{array}{l}\text { Identify effects of } \\
\text { elevated radiation, } \\
\text { temperature, etc. } \\
\text { Perform long-term } \\
\text { adsorption and } \\
\text { leaching studies. }\end{array}$ \\
\hline \multicolumn{5}{|c|}{ Mn-oxide "getters" } \\
\hline $\begin{array}{l}\text { Begin synthesis of } \\
\text { various manganese } \\
\text { oxides. }\end{array}$ & $\begin{array}{l}\text { Begin sorption tests } \\
\text { using non- } \\
\text { radioactive iodine } \\
\text { and rhenium as a } \\
\text { surrogate for Tc. }\end{array}$ & $\begin{array}{l}\text { Continue sorption } \\
\text { tests on promising } \\
\text { materials. }\end{array}$ & $\begin{array}{l}\text { Coordinate with SNL } \\
\text { for testing promising } \\
\text { materials using Tc. }\end{array}$ & $\begin{array}{l}\text { Study promising Mn- } \\
\text { oxide materials } \\
\text { under YMR relevant } \\
\text { conditions. }\end{array}$ \\
\hline \multicolumn{5}{|c|}{ Nanoporous phosphate "getters" for Tc, Np, and I } \\
\hline $\begin{array}{l}\text { Begin templated } \\
\text { synthesis of } \\
\text { nanoporous and } \\
\text { doped lanthanide and } \\
\text { Ti/Zr phosphates. }\end{array}$ & $\begin{array}{l}\text { Conduct Tc sorption } \\
\text { tests to evaluate the } \\
\text { effect of structure, } \\
\text { pore size, surface } \\
\text { charge and dopants. }\end{array}$ & $\begin{array}{l}\text { Evaluate Tc sorption } \\
\text { on } \mathrm{Ti} / \mathrm{Zr} \text { phosphates } \\
\text { and study the } \\
\text { viability of } \mathrm{Fe}, \mathrm{V} \text {, } \\
\text { and } \mathrm{Bi} \text { phosphates. }\end{array}$ & $\begin{array}{l}\text { Continue Tc sorption } \\
\text { tests on promising } \\
\text { materials. }\end{array}$ & $\begin{array}{l}\text { Test Np sorption of } \\
\mathrm{Ti} / \mathrm{Zr} \text { phosphates and } \\
\text { study effect on } \\
\text { nanoporous getters } \\
\text { of superposition of } \\
\text { hierarchical pore } \\
\text { structures. }\end{array}$ \\
\hline \multicolumn{5}{|c|}{ Mesoporous Tc and I "getters" } \\
\hline $\begin{array}{l}\text { Develop protocols } \\
\text { for synthesizing } \\
\text { mesoporous } \\
\text { materials and for } \\
\text { coating mixed oxides } \\
\text { on mesoporous } \\
\text { silica. }\end{array}$ & $\begin{array}{l}\text { Continue to develop } \\
\text { synthesis protocols. } \\
\text { Conduct preliminary } \\
\text { sorption tests. Begin } \\
\text { synthesis of complex } \\
\text { nanoporous materials } \\
\text { with multiple } \\
\text { functional groups. }\end{array}$ & $\begin{array}{l}\text { Continue synthesis } \\
\text { of complex } \\
\text { nanoporous materials } \\
\text { with multiple } \\
\text { functional groups. } \\
\text { Begin extensive } \\
\text { sorption tests. }\end{array}$ & $\begin{array}{l}\text { Refine surface } \\
\text { chemistry and pore } \\
\text { structure. Begin to } \\
\text { develop engineered } \\
\text { forms }\end{array}$ & $\begin{array}{l}\text { Optimize the } \\
\text { nanoporous materials } \\
\text { and engineered } \\
\text { forms. Complete } \\
\text { laboratory testing of } \\
\text { sorption behavior. }\end{array}$ \\
\hline
\end{tabular}




\begin{tabular}{|c|c|c|c|c|}
\hline \multicolumn{5}{|c|}{ Modeling LDH long-term performance } \\
\hline $\begin{array}{l}\text { Quantum mechanical } \\
\text { modeling: } a b \text { initio } \\
\text { calculations will be } \\
\text { performed to obtain a } \\
\text { better understanding } \\
\text { of the interactions of } \\
\mathrm{TcO}_{4}^{-} \text {with internal } \\
\text { surfaces of } \mathrm{LDH} \\
\text { materials. }\end{array}$ & $\begin{array}{l}\text { Classical fluid } \\
\text { molecular dynamics: } \\
\text { Simulations based on } \\
\text { the density } \\
\text { functional theory } \\
\text { will be performed to } \\
\text { investigate the } \\
\text { behaviors of both } \\
\text { solvent and ions } \\
\text { within confined } \\
\text { environments } \\
\text { internal to LDH with } \\
\text { various interlayer } \\
\text { spacing. }\end{array}$ & $\begin{array}{l}\text { Surface } \\
\text { complexation model: } \\
\text { Based on sorption } \\
\text { data and molecular } \\
\text { modeling results, we } \\
\text { will extend the } \\
\text { existing surface } \\
\text { complexation models } \\
\text { to a nano- } \\
\text { confinement } \\
\text { environment in LDH, } \\
\text { using parameters } \\
\text { determined from the } \\
\text { molecular modeling } \\
\text { calculations and } \\
\text { from sorption } \\
\text { experiments. }\end{array}$ & $\begin{array}{l}\text { Thermodynamic } \\
\text { modeling: This } \\
\text { activity focuses on } \\
\text { developing.a } \\
\text { thermodynamic } \\
\text { model for layered } \\
\text { double hydroxides } \\
\text { (LDH). This model } \\
\text { will predict the } \\
\text { Gibbs free energy of } \\
\text { formation of LDHs } \\
\text { and phase stability as } \\
\text { a function of } \\
\text { compositions of both } \\
\text { (layer-forming) } \\
\text { cations and interlayer } \\
\text { anions. }\end{array}$ & $\begin{array}{l}\text { Adaptation of the } \\
\mathrm{EQ} 3 / 6 \text { database to } \\
\text { model the aqueous } \\
\text { speciation of Tc, I, } \\
\text { and } \mathrm{Np} \text { in the unique } \\
\text { range of solutions } \\
\text { likely to occur in the } \\
\text { invert. }\end{array}$ \\
\hline \multicolumn{5}{|c|}{ Ab initio modeling of Tc interactions with $\mathrm{Ti} / \mathrm{Zr}$ phosphate surfaces } \\
\hline $\begin{array}{l}\text { Conduct surface } \\
\text { structure refinements } \\
\text { and compute } \\
\text { energetics by } \\
\text { periodic structure } \\
\text { optimization. }\end{array}$ & $\begin{array}{l}\text { Study the effects of } \\
\text { metal cation } \\
\text { substitutions on } \\
\text { nanopore surface } \\
\text { structure, protonation } \\
\text { and energetics. }\end{array}$ & $\begin{array}{l}\text { Determine likely } \\
\text { binding } \\
\text { conformations of } \mathrm{Tc} \\
\text { on the nanopore } \\
\text { surfaces. Conduct } a b \\
\text { initio molecular } \\
\text { dynamic simulations. }\end{array}$ & $\begin{array}{l}\text { Extend the binding } \\
\text { conformation studies } \\
\text { to structurally more } \\
\text { complex anionic } \\
\mathrm{Np}(\mathrm{V}) \text { species. }\end{array}$ & $\begin{array}{l}\text { Extend the } a b \text { initio } \\
\text { molecular dynamic } \\
\text { simulations to study } \\
\text { the adsorption of } \\
\text { iodine species. }\end{array}$ \\
\hline \multicolumn{5}{|c|}{ Speciation and bonding of Tc in nanoporous "getter" materials } \\
\hline $\begin{array}{l}\text { Develop speciation } \\
\text { data for Tc. Study } \\
\text { surface charge in } \\
\text { nanopores and its } \\
\text { effects on Tc } \\
\text { binding. }\end{array}$ & $\begin{array}{l}\text { Conduct detailed } \\
\text { studies of surface } \\
\text { charge as a function } \\
\text { of } \mathrm{pH} \text { and ionic } \\
\text { strength and } \mathrm{Tc} \\
\text { binding in } \\
\text { nanoporous } \\
\text { phosphates. }\end{array}$ & $\begin{array}{l}\text { Develop surface } \\
\text { complexation model } \\
\text { and conduct XRD, } \\
\text { EXAFS/XANES to } \\
\text { verify and improve. }\end{array}$ & $\begin{array}{l}\text { Extend studies of } \\
\mathrm{TcO}_{4}^{-} \text {binding to } \\
\text { structurally more } \\
\text { complex anionic } \\
\text { species (e.g., } \mathrm{Np}(\mathrm{V}) \text {. }\end{array}$ & $\begin{array}{l}\text { Continue the bidning } \\
\text { studies of } \mathrm{Np}(\mathrm{V}) \text { on } \\
\text { the nanoporous } \\
\text { surfaces. }\end{array}$ \\
\hline \multicolumn{5}{|c|}{ Kinetic and equilibrium sorption experiments for I and Tc } \\
\hline $\begin{array}{l}\text { Begin development } \\
\text { of standardized } \\
\text { testing protocols. }\end{array}$ & $\begin{array}{l}\text { Finalize development } \\
\text { of standardized } \\
\text { testing protocols. } \\
\text { Conduct preliminary } \\
\text { testing of sorption } \\
\text { behavior of } \\
\text { promising getters. }\end{array}$ & $\begin{array}{l}\text { Perform extensive } \\
\text { testing of sorption } \\
\text { behavior of } \\
\text { promising getters. } \\
\text { Begin analyzing } \\
\text { iodine getters to } \\
\text { determine } \\
\text { mechanisms. }\end{array}$ & $\begin{array}{l}\text { Conduct sorption } \\
\text { studies with waste } \\
\text { package corrosion } \\
\text { products. }\end{array}$ & $\begin{array}{l}\text { Complete laboratory } \\
\text { testing of candidate } \\
\text { getter materials. }\end{array}$ \\
\hline
\end{tabular}

\section{SUMMARY OF BENEFITS TO OFFICE OF CIVILIAN RADIOACTIVE WASTE MANAGEMENT}

Introducing highly efficient anion "getters" into the repository inverts could significantly reduce the predicted radiation doses from potential radionuclide releases. The benefits of this research to the YMP are potentially twofold. First, the deployment of "getters" could reduce the reliance of total systems performance on other engineered barrier components (such as drip shields used to minimize corrosion of waste package materials), which could lead to a simplification of the current engineering design and, therefore, save costs. Second, deployment of "getters" could increase confidence in 
TSPA calculations of repository performance for long-term radionuclide containment. Therefore, the research and development of "getter" materials can potentially reduce the total life cycle cost of YMR through modification of engineered barrier systems including waste packages and drip shields. 


\section{REFERENCES}

1. US EPA 40 CFR part 197-64, 64 FR 46976.

2. Moore, R.C., K. Holt, C. Sanchez, H. Zhoa, F. Salas, A. Hasan and D. Lucero (2002) SAND2002-3642.

3. Rard, J.A., M.H. Rand, J.R. Thornback, H. Warner (1991) Journal of Chemical Physics, 94(9), 6336-7.

4. Wang, S., H.Q. Luo, Y.Z. Wang, G.Q. Gong (2003) Spectrochimica Acta Part A, $59(6), 1139-44$.

$\S$ Sandia National Laboratories is a multi-program laboratory operated by Sandia Corporation, a Lockheed Martin company, for the United States Department of Energy's National Nuclear Security Administration under Contract DE-AC0494AL85000.

DOE Acknowledgement:

This report was prepared by Sandia National Laboratories pursuant to a contract funded by the United States Department of Energy (DOE), Office of Civilian Radioactive Waste Management (OCRWM), Office of Science and Technology and International (OST\&I), and neither, Sandia National Laboratories nor any of its contractors or subcontractors nor the DOE/OCRWM/OST\&I, nor any person acting on behalf of either:

Makes any warranty or representation, express or implied, with respect to the accuracy, completeness, or usefulness of the information contained in this report, or that the use of any information, apparatus, method, or process disclosed in this report may not infringe privatelyowned rights; or

Assumes any liabilities with respect to the use of, or for damages resulting from the use of, any information, apparatus, method, or process disclosed in this report. Reference herein to any specific commercial product, process, or service by trade name, trademark, manufacturer, or otherwise, does not necessarily constitute or imply its endorsement, recommendation, or favoring by DOE/OCRWM/OST\&I.

The views and opinions of authors expressed herein do not necessarily state or reflect those of the DOE/OCRWM/OST\&I. 